\title{
A Novel Cold-Adapted Leucine Dehydrogenase from Antarctic Sea-Ice Bacterium Pseudoalteromonas sp. ANT178
}

\author{
Yatong Wang ${ }^{\mathbb{D}}$, Yanhua Hou, Yifan Wang ${ }^{\mathbb{D}}$, Lu Zheng, Xianlei Xu, Kang Pan, Rongqi Li and \\ Quanfu Wang *(D)
}

School of Marine Science and Technology, Harbin Institute of Technology, Weihai 264209, China; wangyatong199311@163.com (Y.W.); marry7718@163.com (Y.H.); daid01@126.com (Y.W.); zhenglu0206@126.com (L.Z.); 17863108956@163.com (X.X.); m15662319228@163.com (K.P.); 11263769417@163.com (R.L.)

* Correspondence: wangquanfuhit@hit.edu.cn; Tel./Fax: +86-631-568-7240

Received: 13 September 2018; Accepted: 27 September 2018; Published: 1 October 2018

\begin{abstract}
L-tert-leucine and its derivatives are useful as pharmaceutical active ingredients, in which leucine dehydrogenase (LeuDH) is the key enzyme in their enzymatic conversions. In the present study, a novel cold-adapted LeuDH, psleudh, was cloned from psychrotrophic bacteria Pseudoalteromonas sp. ANT178, which was isolated from Antarctic sea-ice. Bioinformatics analysis of the gene psleudh showed that the gene was $1209 \mathrm{bp}$ in length and coded for a $42.6 \mathrm{kDa}$ protein containing 402 amino acids. PsLeuDH had conserved Phe binding site and $\mathrm{NAD}^{+}$binding site, and belonged to a member of the Glu/Leu/Phe/Val dehydrogenase family. Homology modeling analysis results suggested that PsLeuDH exhibited more glycine residues, reduced proline residues, and arginine residues, which might be responsible for its catalytic efficiency at low temperature. The recombinant PsLeuDH (rPsLeuDH) was purified a major band with the high specific activity of $275.13 \mathrm{U} / \mathrm{mg}$ using a Ni-NTA affinity chromatography. The optimum temperature and $\mathrm{pH}$ for rPsLeuDH activity were $30^{\circ} \mathrm{C}$ and $\mathrm{pH}$ 9.0, respectively. Importantly, rPsLeuDH retained at least $40 \%$ of its maximum activity even at $0{ }^{\circ} \mathrm{C}$. Moreover, the activity of $\mathrm{rPsLeuDH}$ was the highest in the presence of $2.0 \mathrm{M} \mathrm{NaCl}$. Substrate specificity and kinetic studies of rPsLeuDH demonstrated that L-leucine was the most suitable substrate, and the catalytic activity at low temperatures was ensured by maintaining a high $k_{\text {cat }}$ value. The results of the current study would provide insight into Antarctic sea-ice bacterium LeuDH, and the unique properties of $\mathrm{rPLLuDH}$ make it a promising candidate as a biocatalyst in medical and pharmaceutical industries.
\end{abstract}

Keywords: leucine dehydrogenase; cold-adapted; Antarctic bacterium; sea-ice; homology modeling

\section{Introduction}

Leucine dehydrogenase (LeuDH; EC 1.4.1.9), a NAD ${ }^{+}$dependent oxidoreductase, which catalyzes reversible L-leucine and other branched chain L-amino acids deamination reaction to the formation of the corresponding $\alpha$-keto acid [1]. The enzyme was first identified in Bacillus cereus [2], and then was found in some microorganisms Bacillus licheniformis [3], Bacillus sphaericus [4], Citrobacter freundii [5], and Laceyella sacchari [6]. Moreover, crystal structures of the LeuDH from Sporosarcina psychrophila [7] and Bacillus sphaericus have been described [8].

LeuDH is used as a biocatalyst to format amino acids for using in the pharmaceutical industry by catalyzing the corresponding $\alpha$-keto acids [9]. However, some of $\alpha$-keto acids are unstable and degraded during prolonged incubation at moderate temperatures, such as $37^{\circ} \mathrm{C}$ [10]. Importantly, cold-adapted enzymes that exhibit high levels of activity at room temperature $\left(20-25^{\circ} \mathrm{C}\right)$ should be 
useful for converting such unstable $\alpha$-keto acids. What is more, cold-adapted enzymes have better conversion rates, the specificity of substrate and product, fewer by-products, which are required in the modern industry [11]. Although many LeuDHs have already been characterized, only a few cold-adapted LeuDH have been reported, such as LeuDH from Alcanivorax dieselolei [12] and Sporosarcina psychrophila [7].

Antarctic sea-ice, due to its specific geographical location and climate, is considered as an extreme environment on the earth. To develop the ability to withstand the extreme environment, sea-ice microorganisms have evolved several adaptive strategies and would be the new and promising microbial sources of cold-adapted enzymes. In our previous studies, some cold-adapted enzymes were isolated from Antarctic sea-ice bacteria and had become interesting for industrial applications $[13,14]$. It is well-known that L-tert-leucine and its derivatives are useful as pharmaceutical active ingredients and chiral auxiliaries, while LeuDH is a key enzyme for the enzymatic production of L-tert-leucine. Here, we briefly describe the homology modeling, expression, and characterization of cold-adapted LeuDH from Antarctic sea-ice bacterium. This LeuDH had unique properties make it good candidate for future medical and pharmaceutical industry applications.

\section{Results and Discussion}

\subsection{Gene Cloning and Sequence Analysis}

The psleudh gene was amplified from genomic DNA of the strain ANT178. It consisted of an ORF of $1209 \mathrm{bp}$, encoded a protein of 402 amino acid resides with a theoretical pI of 5.08. Furthermore, the DNA sequence of psleudh was submitted to the GenBank database with the accession number of MH322031. Based on sequences alignment, PsLeuDH showed the highest sequence similarity $(88.0 \%)$ with LeuDH from Pseudoalteromonas nigrifaciens (ASM53600), followed by a sequence similarity of 65.0\% with LeuDH from Colwellia piezophila (WP_019029130). More importantly, PsLeuDH had a conserved Phe binding site (I344) and NAD ${ }^{+}$binding sites (G233, G235, T236, V237, D256, I257, A261, C290, A291, C312, and N314). The coenzyme binding domain of $\mathrm{NAD}^{+}$in LeuDH was capable of catalyzing the reversible oxidative deamination of L-leucine and several other branched chain amino acids to form the corresponding 2-oxo acid derivatives. This domain could be classified as a member of the Rossmann fold superfamily, comprising a plurality of different dehydrogenases, wherein the amino acid dehydrogenase family comprises a common feature: a beta-sheet-alpha helix-beta sheet conformation [15]. PsLeuDH had this structural feature from Figure 1, further demonstrating that PsLeuDH was a member of the Glu/Leu/Phe/Val dehydrogenase family. 

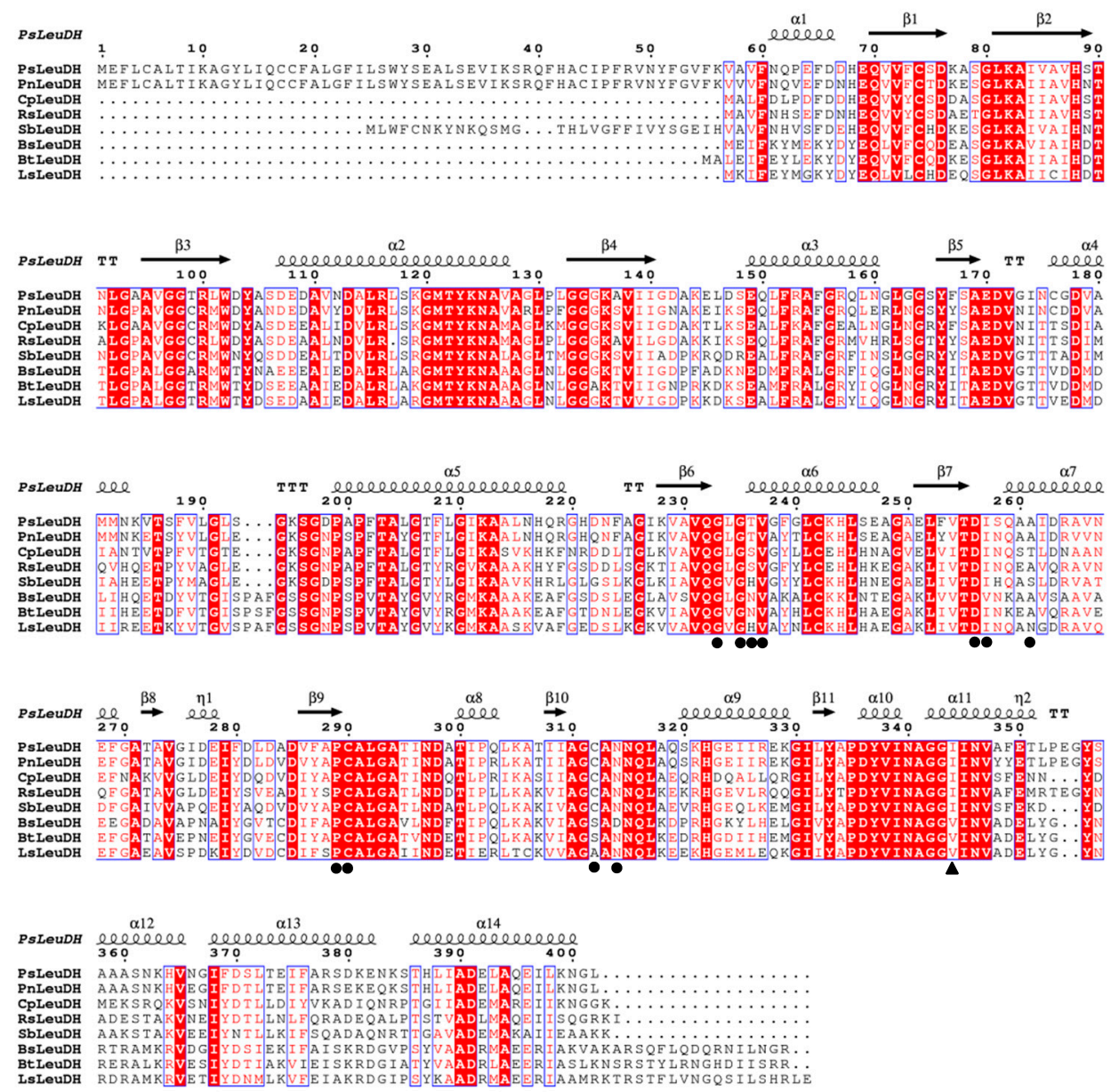

Figure 1. Amino acid sequence alignment of PsLeuDH and related LeuDH. PsLeuDH, Pseudoalteromonas sp. ANT178 LeuDH (MH322031); PnLeuDH, Pseudoalteromonas nigrifaciens (ASM53600); C $p$ LeuDH, Colwellia piezophila (WP_019029130); RsLeuDH, Rheinheimera salexigens (WP_070050751); SbLeuDH, Shewanella baltica BA175 (AEG11165); BsLeuDH, Bacillus sphaericus ATCC4525 (PDB ID:1LEH); BtLeuDH, Bacillus thuringiensis (WP_001162678); and LsLeuDH, Laceyella sacchari (KR065697). $\bullet$, NAD binding site; $\mathbf{\Lambda}$, Phe binding site.

\subsection{Homology Modeling and Analysis of PsLeuDH}

BsLeuDH (PDB ID:1LEH), encoded 364 amino acids, was isolated from mesophilic bacteria Bacillus sphaericus ATCC4525 [16], which exhibited the highest sequence identity (51\%) to PsLeuDH using DALI server. The comparative analysis of the 3D structure of PsLeuDH and the mesophilic enzyme Bs-LeuDH was shown in Figure 2. It could be seen that two LeuDHs had a similar NAD ${ }^{+}$ binding site and Phe binding site. 


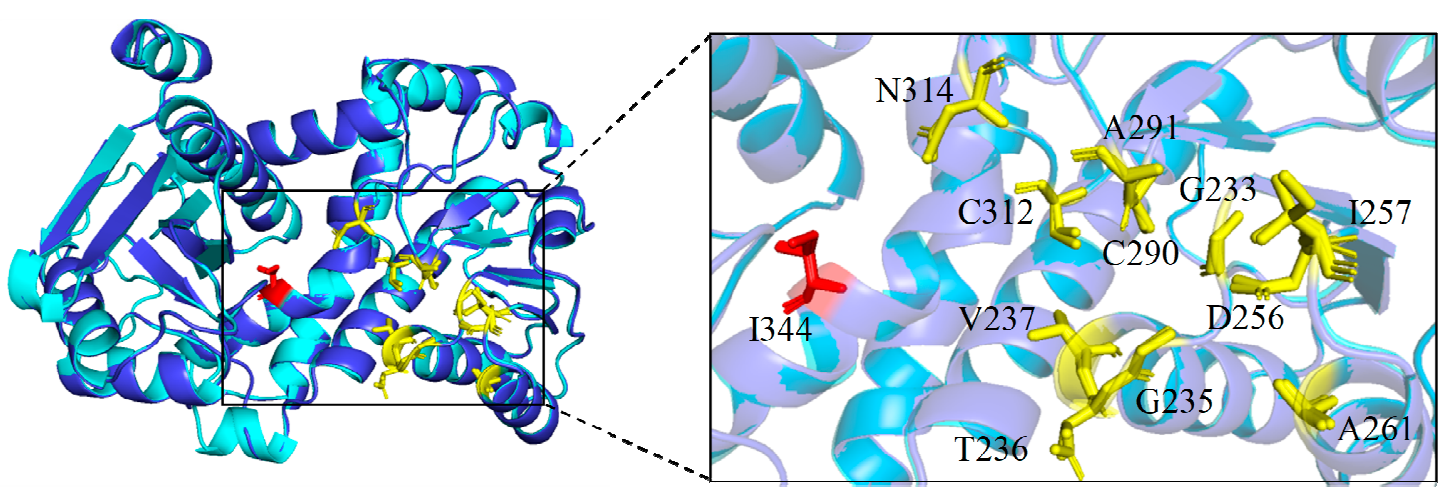

Figure 2. Three-dimensional structure comparison of PsLeuDH and BsLeuDH model. PsLeuDH, tv-blue; BsLeuDH, cyan; $\mathrm{NAD}^{+}$binding site, yellow ball stick model; Phe binding site, red ball stick model.

Comparison of structural adaptation characteristics and amino acid substitutions between PsLeuDH and BsLeuDH was shown in Table 1. It can be seen that PsLeuDH exhibited several cold-adapted features. Firstly, the number of electrostatic interactions of PsLeuDH was less than BsLeuDH, which might make the structure of PsLeuDH more flexible [17]. PsLeuDH also had less hydrophobic interactions compared to BsLeuDH, it might make PsLeuDH less rigid and contributed to decrease in structural stability [18]. Secondly, PsLeuDH revealed higher glycine residues and fewer proline and arginine residues that could affect the cold-adapted proteins properties which might offer higher flexibility to proteins [19]. Several amino acid residues in BsLeuDH were replaced by glycine residues in PsLeuDH. The glycine residues might improve the flexibility of the active site, and regulate the entropy of protein unfolding [10], thus probably improving the catalytic efficiency of the enzyme at low temperature. Additionally, proline might reduce the configuration entropy of the unfolding of protein molecules [20] and reduce the stability of enzyme molecules. Additionally, the stability of enzyme was also a significant factor to determine its catalytic characteristics. Some arginine residues in PsLeuDH were replaced by other residues at the same position in BsLeuDH. One of the stability factors in protein structure referred to salt bridges formed by arginine residues [19], arginine might make protein molecules more stable through ionic interaction. Compared with mesophilic enzyme BsLeuDH, PsLeuDH had higher flexibility and lower thermal stability, resulting in higher catalytic efficiency at low temperature [21].

Table 1. Comparison of structural adaption features and amino acid substitutions between PsLeuDH and its homolog (BsLeuDH).

\begin{tabular}{|c|c|c|c|}
\hline Parameters & PsLeuDH & Bs-LeuDH & Expected Effect on PsLeuDH \\
\hline \multicolumn{3}{|l|}{ Electrostatic interactions } & \multirow{5}{*}{ Protein stability } \\
\hline Salt Bridge (2.5 to 4.0$)$ & 17 & 22 & \\
\hline Hydrogen Bonds $(\leq 3.3 \AA \AA$ & 368 & \multirow{2}{*}{$\begin{array}{c}403 \\
11\end{array}$} & \\
\hline Cation-pi interactions & 3 & & \\
\hline Aromatic interactions & 6 & 8 & \\
\hline Hydrophobic interactions & 227 & 318 & Thermolability \\
\hline Glycine residues & 42 & 36 & \multirow{5}{*}{ Flexibility } \\
\hline Proline residues & 9 & 11 & \\
\hline Arginine residues & 10 & 17 & \\
\hline \multirow{2}{*}{$\begin{array}{c}\text { Glycine substitution } \\
\text { (PsLeuDH } \rightarrow \text { BsLeuDH) } \\
\text { Proline substitution } \\
\text { (PsLeuDH } \rightarrow \text { BsLeuDH) }\end{array}$} & \multicolumn{2}{|c|}{$\begin{array}{c}\mathrm{G} 163 \rightarrow \mathrm{N} 107, \mathrm{G} 177 \rightarrow \mathrm{D} 121, \mathrm{G} 238 \rightarrow \mathrm{A} 185, \mathrm{G} 240 \rightarrow \\
\mathrm{A} 187, \mathrm{G} 275 \rightarrow \mathrm{A} 222, \mathrm{G} 401 \rightarrow \mathrm{V} 346\end{array}$} & \\
\hline & \multicolumn{2}{|c|}{ A94 $\rightarrow$ P38, A143 $\rightarrow$ P87, S320 $\rightarrow$ P267, S385 $\rightarrow$ P330 } & \\
\hline \multirow{2}{*}{$\begin{array}{c}\text { Proline substitution } \\
(\text { PsLeuDH } \rightarrow \text { BsLeuDH) } \\
\text { Arginine substitution } \\
(\text { PsLeuDH } \rightarrow \text { BsLeuDH) }\end{array}$} & \multicolumn{2}{|c|}{$\mathrm{P} 131 \rightarrow \mathrm{N} 75, \mathrm{P} 63 \rightarrow \mathrm{M} 7$} & \multirow[t]{2}{*}{ Stability } \\
\hline & \multicolumn{2}{|c|}{$\mathrm{R} 219 \rightarrow \mathrm{F} 166, \mathrm{R} 264 \rightarrow \underset{\mathrm{I} 323}{\mathrm{~A} 211, \mathrm{R} 327} \rightarrow \mathrm{H} 274, \mathrm{R} 378 \rightarrow$} & \\
\hline
\end{tabular}




\subsection{Expression and Purification of the rPsLeuDH}

The gene coding for the PsLeuDH was cloned into the pET-28a (+) vector and expressed in E. coli BL21 (DE3) under IPTG induction (Figure 3, Lane 3). rPsLeuDH was purified in a single step using His-tag affinity chromatography. A major band was observed on SDS-PAGE with about the molecular weight $44.4 \mathrm{kDa}$ (Figure 3, Lane 4,5). It is noteworthy that the last purified rPsLeuDH exhibited the highest specific activity of $275.13 \mathrm{U} / \mathrm{mg}$.

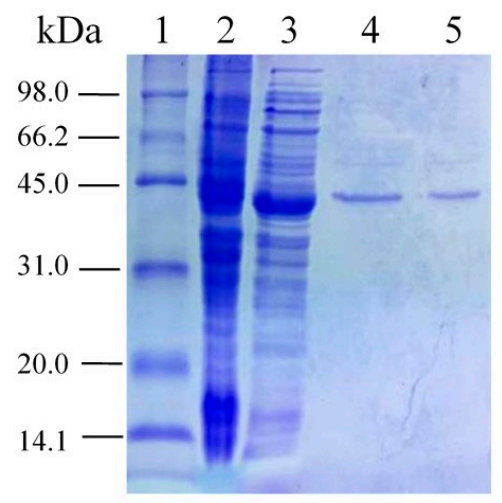

Figure 3. Expression and purification analysis of PsLeuDH. Lane 1: molecular weight standard marker; Lane 2: crude extract from the BL21/pET-28a (+); Lane 3: crude extract from the BL21/pET-28a (+)-PsLeuDH with IPTG induction; Lane 4: rPsLeuDH eluted with $50 \mathrm{mM}$ imidazole; Lane 5: rPsLeuDH eluted with $100 \mathrm{mM}$ imidazole.

\subsection{Effects of Temperature and $p H$ on Activity and Stability of $r P_{s} L e u D H$}

The temperature characteristic of $\mathrm{rPsLeuDH}$ was shown in Figure 4a. It exhibited the highest activity at $30^{\circ} \mathrm{C}$, and that of a cold-adapted LeuDH was $30^{\circ} \mathrm{C}$ [12], whereas thermophilic LeuDH was approximately $40-65^{\circ} \mathrm{C}[6,22]$, or $\left(60-75^{\circ} \mathrm{C}\right)$ [5]. It is worth pointing out that $\mathrm{rPsLeuDH}$ retained $40 \%$ of the highest activity at $0{ }^{\circ} \mathrm{C}$, suggested that the enzyme is a cold-adapted enzyme [23]. Furthermore, the thermostability of rPsLeuDH was assessed in Figure $4 \mathrm{~b}$. It was stable and retained $85 \%$ of its initial activity after incubating at $30{ }^{\circ} \mathrm{C}$ after $120 \mathrm{~min}$. While, after incubating at $50{ }^{\circ} \mathrm{C}$ for $20 \mathrm{~min}$, it was only $30 \%$ of its activity lower than other cold-adapted LeuDHs from Alcanivorax dieselolei [12] and Sporosarcina psychrophila [7]. However, thermostable LeuDH could retain full activity after incubation at $65^{\circ} \mathrm{C}$ for $10 \mathrm{~min}$ [24]. The above results indicated that rPsLeuDH had thermal instability, which was another significant feature of cold-adapted enzyme [25]. The effect of $\mathrm{pH}$ on rPsLeuDH activity was shown in Figure 4c. The activity of rPsLeuDH was higher under alkaline conditions ( $\mathrm{pH}$ 7.0-10.0), with the highest activity at $\mathrm{pH}$ 9.0. Similar results were described in other LeuDHs such as Sporosarcina psychrophile ( $\mathrm{pH}$ 8.5-11.0) [7], Laceyella sacchari ( $\mathrm{pH} 9.5-11$ ) [6] and Citrobacter freundii ( $\mathrm{pH} 9.0$ to 11.0) [5]. After $30 \mathrm{~min}$ of exposure to $\mathrm{pH}$ 6.0-10.0, the stability of rPsLeuDH showed a similar pattern with that of the activity response to $\mathrm{pH}$ (Figure $4 \mathrm{~d}$ ). This broad range of $\mathrm{pH}$ dependence for the activity and stability made the rPsLeuDH probably useful for medical industrial applications. 


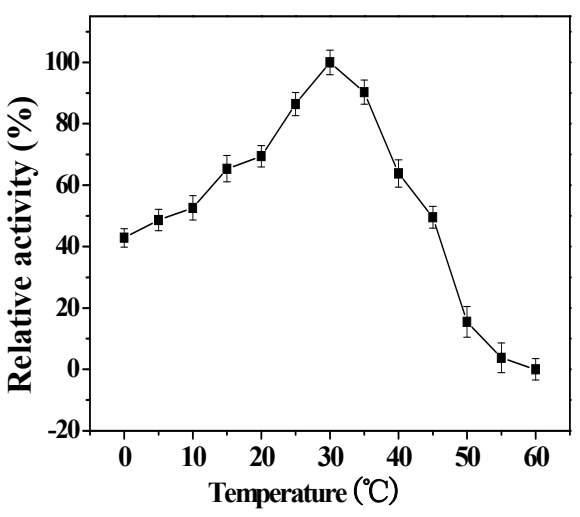

(a)

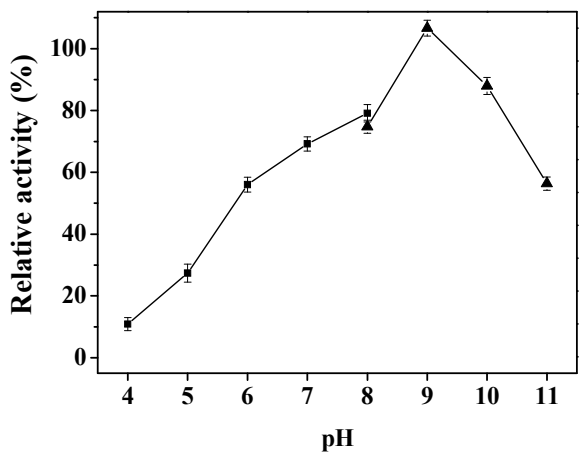

(c)

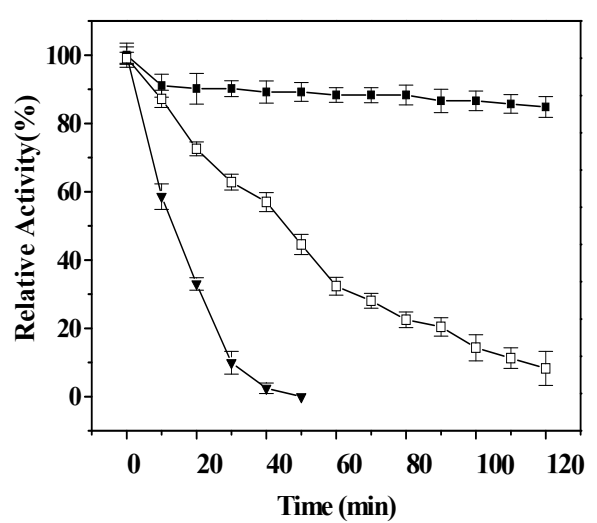

(b)

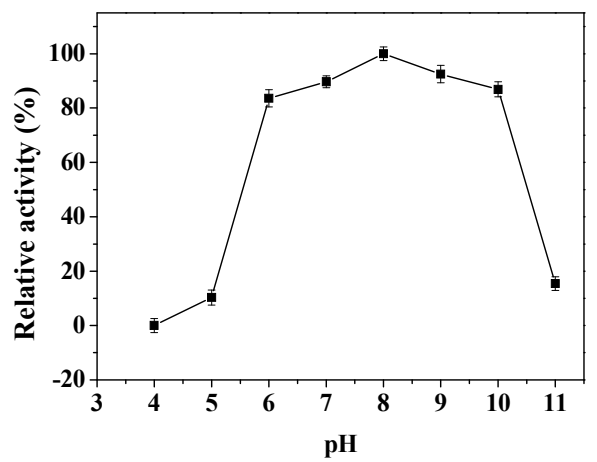

(d)

Figure 4. Effects of temperature and $\mathrm{pH}$ on the activity and stability of rPsLeuDH. (a) Effect of temperature on the activity of rPsLeuDH. (b) Effect of temperature on the stability of rPsLeuDH. ( $\mathbf{\square}) 30$ ${ }^{\circ} \mathrm{C},(\square) 40{ }^{\circ} \mathrm{C},(\boldsymbol{\nabla}) 50{ }^{\circ} \mathrm{C}$. (c) Effect of $\mathrm{pH}$ on the activity of rPsLeuDH. (d) Effect of $\mathrm{pH}$ on the stability of rPsLeuDH. Data are presented as mean $\pm \mathrm{SD}(n=3)$.

\subsection{Effects of $\mathrm{NaCl}$ Concentration and Different Reagents on the Activity of PsLeuDH}

The effect of $\mathrm{NaCl}$ concentration on the rPsLeuDH activity was shown in Figure 5. It could be seen that rPsLeuDH was stable at $0-3.0 \mathrm{M} \mathrm{NaCl}$, with the highest activity at $2.0 \mathrm{M} \mathrm{NaCl}$, which may be related to high salinity in the Antarctic sea ice environment. The similar result was also found in LeuDH from Bacillus licheniformis [3] and Thermoactinomyces intermedius [24] after high salt concentration treatment. The effect of various reagents on the rPsLeuDH activity was listed in Table 2. rPsLeuDH was completely inhibited by $1 \mathrm{mM} \mathrm{Pb}\left(\mathrm{NO}_{3}\right)_{2}$ and $\mathrm{BaCl}_{2}$. Inhibitions by $1 \mathrm{mM} \mathrm{CrCl}_{2}$ and $\mathrm{CdCl}_{2}$ were $86.7 \%$ and $92.4 \%$, respectively, while only partially inhibited by other metals salt in some extent. In addition, rPsLeuDH was sensitive to Thiourea and ethanol, but Triton X-100 kept the enzyme activity.

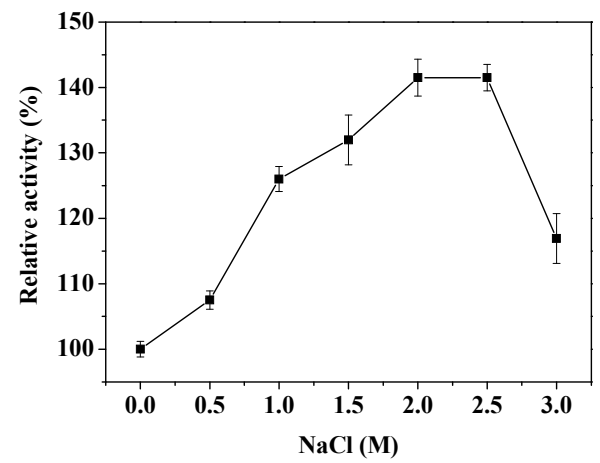

Figure 5. Effect of salt concentration on the activity of rPsLeuDH. 
Table 2. Effects of different reagents on the activity of rPsLeuDH.

\begin{tabular}{cccccc}
\hline Reagent & Concentration & Relative Activity (\%) & Reagent & Concentration & Relative Activity (\%) \\
\hline None & & $100 \pm 0.0$ & & & \\
$\mathrm{KCl}$ & $1 \mathrm{mM}$ & $99.7 \pm 1.6$ & $\mathrm{KCl}$ & $5 \mathrm{mM}$ & $40.0 \pm 1.9$ \\
$\mathrm{CoCl}$ & $1 \mathrm{mM}$ & $90.1 \pm 1.7$ & $\mathrm{CoCl}$ & $5 \mathrm{mM}$ & $70.0 \pm 2.0$ \\
$\mathrm{MgCl}_{2}$ & $1 \mathrm{mM}$ & $87.9 \pm 0.8$ & $\mathrm{MgCl}_{2}$ & $5 \mathrm{mM}$ & $65.8 \pm 1.2$ \\
$\mathrm{CaCl}_{2}$ & $1 \mathrm{mM}$ & $87.9 \pm 0.4$ & $\mathrm{CaCl}_{2}$ & $5 \mathrm{mM}$ & $68.1 \pm 0.9$ \\
$\mathrm{ZnCl}_{2}$ & $1 \mathrm{mM}$ & $80.0 \pm 2.5$ & $\mathrm{ZnCl}_{2}$ & $5 \mathrm{mM}$ & $72.2 \pm 2.0$ \\
$\mathrm{FeCl}_{2}$ & $1 \mathrm{mM}$ & $75.1 \pm 2.2$ & $\mathrm{FeCl}_{2}$ & $5 \mathrm{mM}$ & $62.4 \pm 1.7$ \\
$\mathrm{CuCl}_{2}$ & $1 \mathrm{mM}$ & $61.0 \pm 2.2$ & $\mathrm{CuCl}_{2}$ & $5 \mathrm{mM}$ & $41.0 \pm 1.5$ \\
$\mathrm{HgCl}_{2}$ & $1 \mathrm{mM}$ & $29.2 \pm 0.3$ & $\mathrm{HgCl}_{2}$ & $5 \mathrm{mM}$ & $12.3 \pm 1.9$ \\
$\mathrm{CrCl}_{2}$ & $1 \mathrm{mM}$ & $13.3 \pm 0.3$ & $\mathrm{CrCl}_{2}$ & $5 \mathrm{mM}$ & $5.8 \pm 2.9$ \\
$\mathrm{CdCl}_{2}$ & $1 \mathrm{mM}$ & $7.6 \pm 0.5$ & $\mathrm{CdCl}_{2}$ & $5 \mathrm{mM}$ & $0.0 \pm 0.0$ \\
$\mathrm{~Pb}\left(\mathrm{NO}_{3}\right)_{2}$ & $1 \mathrm{mM}$ & $0.0 \pm 0.0$ & $\mathrm{~Pb}_{2}\left(\mathrm{NO}_{3}\right)_{2}$ & $5 \mathrm{mM}$ & $0.0 \pm 0.0$ \\
$\mathrm{BaCl}$ & $1 \mathrm{mM}$ & $0.0 \pm 0.0$ & $\mathrm{BaCl}_{2}$ & $5 \mathrm{mM}$ & $0.0 \pm 0.0$ \\
$\mathrm{EDTA}$ & $1 \mathrm{mM}$ & $91.8 \pm 2.7$ & $\mathrm{EDTA}$ & $5 \mathrm{mM}$ & $84.2 \pm 2.1$ \\
$\mathrm{Thiourea}$ & $1 \mathrm{mM}$ & $51.5 \pm 4.0$ & Thiourea & $5 \mathrm{mM}$ & $34.3 \pm 2.6$ \\
Triton X-100 & $0.2 \%$ & $102.7 \pm 1.4$ & Ethanol & $25 \%$ & $67.5 \pm 1.4$ \\
\hline
\end{tabular}

\subsection{The Substrate Specificity Analysis and Kinetic Parameters of rPsLeuDH}

The substrate specificity analysis of rPsLeuDH was listed in Table 3. It could catalyze and utilize five substrates, indicating that $\mathrm{rPsLeuDH}$ possessed a broad spectrum of substrates in catalytic oxidation reaction. L-leucine was the most suitable substrate for $\mathrm{rPsLeuDH}$, which was the similar with other microbial LeuDH [6,22]. The kinetic parameters of rPsLeuDH were determined. $K_{\mathrm{m}}$ and $V_{\mathrm{m}}$ of L-leucine were calculated as $0.33 \mathrm{mM}$ and $15.24 \mu \mathrm{mol} / \mathrm{min} \cdot \mathrm{mg}$, respectively. Besides, the $k_{\text {cat }}$ value of L-leucine was $30.13 / \mathrm{s}$, demonstrating that rPsLeuDH had a high affinity to substrates and was conducive to improving catalytic efficiency at low temperature.

Table 3. Substrate specificity analysis of rPsLeuDH.

\begin{tabular}{|c|c|c|c|c|}
\hline Substrate & $V_{\mathrm{m}}(\mu \mathrm{mol} / \mathrm{min} \cdot \mathrm{mg})$ & $K_{\mathrm{m}}(\mathrm{mM})$ & $k_{\text {cat }}(1 / \mathrm{s})$ & $k_{\mathrm{cat}} / K_{\mathrm{m}}\left(\mathrm{mM}^{-1} \mathrm{~s}^{-1}\right.$ \\
\hline L-lecine & 15.24 & 0.33 & 30.13 & 91.30 \\
\hline L-tyrosine & 13.35 & 0.48 & 26.39 & 54.98 \\
\hline L-proline & 10.52 & 0.64 & 20.80 & 32.50 \\
\hline DL-methionine & 8.38 & 0.75 & 16.57 & 22.09 \\
\hline L-arginine & 7.13 & 0.84 & 14.09 & 16.77 \\
\hline
\end{tabular}

\subsection{The Thermodynamic Parameters of rPsLeuDH}

Thermodynamic parameters such as $\Delta H, \Delta S$ and $\Delta G$ at different temperature $\left(0-30{ }^{\circ} \mathrm{C}\right)$ were calculated and listed in Table 4. At $0,10,20$, and $30{ }^{\circ} \mathrm{C}$, the $k_{\text {cat }}$ value of rPsLeuDH were 12.25, $14.96,20.20$ and $30.13 / \mathrm{s}$, respectively, indicating that the $k_{\text {cat }}$ value increased with increasing temperature, which was similar to the $k_{\text {cat }}$ change trend of cold-adapted $\beta$-D-galactosidase at different temperatures [26]. rPsLeuDH also exhibited lower $\Delta H, \Delta S$ and $\Delta G$ and higher $k_{\text {cat }}$ at low temperature, as compared to mesophilic enzyme, which may be mainly related to the conformation of cold adapted protein [27]. On the other hand, it may also be related to increasing the efficiency of binding of the substrate to the catalytic site [28].

Table 4. Thermodynamic parameter of the rPsLeuDH.

\begin{tabular}{ccccc}
\hline Temperature $\left({ }^{\circ} \mathbf{C}\right)$ & $\boldsymbol{\Delta} \boldsymbol{H}(\mathbf{K J} / \mathbf{m o l})$ & $\boldsymbol{\Delta} \boldsymbol{( J / m o l ~ K )}$ & $\boldsymbol{\Delta} \boldsymbol{G}(\mathbf{K J} / \mathbf{m o l})$ & $\boldsymbol{k}_{\text {cat }}(\mathbf{1} / \mathbf{s})$ \\
\hline 0 & 18.27 & -156.45 & 61.01 & 12.25 \\
10 & 18.19 & -157.75 & 62.90 & 14.96 \\
20 & 18.11 & -158.02 & 64.43 & 20.20 \\
30 & 18.02 & -157.28 & 65.70 & 30.13 \\
\hline
\end{tabular}




\section{Materials and Methods}

\subsection{Microorganisms and Growth Conditions}

The strain Pseudoalteromonas sp. ANT178, isolated from sea ice in Antarctica $\left(68^{\circ} 30^{\prime} \mathrm{E}, 65^{\circ} 00^{\prime} \mathrm{S}\right)$, was used as a source of $p$ sleudh gene. The strain ANT178 was cultivated in the 2216E sea water medium (initial $\mathrm{pH} 7.5,5 \mathrm{~g} / \mathrm{L}$ peptone, and $1 \mathrm{~g} / \mathrm{L}$ yeast extract) for $96 \mathrm{~h}$ at $12{ }^{\circ} \mathrm{C}$. E. coli BL21 (DE3) was used as the plasmid host.

\subsection{Sequence Analysis of LeuDH Gene}

The open reading frame and amino acid sequences of psleudh gene were computed (https:/ /www. ncbi.nlm.nih.gov/orffinder/). The theoretical molecular weight and $\mathrm{pI}$ were also analyzed using the ExPASy Compute $\mathrm{pI} / \mathrm{Mw}$ tool (http://web.expasy.org/computepi). Multiple sequence alignment of the amino acids of PsLeuDH was performed using Bioedit 7.2 and ESPript 3.0 [29].

\subsection{Protein Homology Modeling}

A homology model of LeuDH was built with SWISS-MODEL. LeuDH from mesophilic bacteria Bacillus sphaericus ATCC4525 (PDB ID:1LEH) [16] was selected as the template. The structure figures were created with PyMOL software (DeLano Scientific LLC, San Carlos, CA, USA). Salt bridges were carried out using VMD 1.9.3. (University of lllinois Urbana-Champaign, Champaign, IL, USA). For the hydrogen bonds, a cut-off distance of $3.3 \AA$ was set. Cation-pi interactions, aromatic interactions, ionic interactions, and hydrogen bonds were predicted by the Protein Interactions Calculator program (http:/ / pic.mbu.iisc.ernet.in).

\subsection{Molecular Cloning, Expression and Purification of rPsLeuDH}

The genome of Pseudoalteromonas sp. ANT178 was sequenced and annotated using high-throughput technologies (data not shown). The full-length gene of psleudh was amplified by PCR using the primers $5^{\prime}$-GATGGATCCATGGAATTT TTATGTG-3' (BamHI site underlined) and 5'-CAGAAGCTTGAAGACCGTTTT TAAG-3' (HindIII site underlined) according to its genome sequence. PCR was performed with Taq DNA polymerase (TaKaRa Bio, Dalian, China). The product was then directly cloned into the corresponding sites of the pET-28a (+) vector and transformed into E. coli BL21. The transformants with the psleudh gene were grown in Luria-Bertani (LB) medium supplemented with $100 \mathrm{mg} / \mathrm{L}$ kanamycin and cultured by shaking at $37^{\circ} \mathrm{C}$ until the $\mathrm{OD}_{600}$ reached $0.6-0.8$. Then, $1.0 \mathrm{mM}$ sopropyl- $\beta$-D-thiogalactopyranoside (IPTG) was added for induction. The bacterial cells were cultured at $37^{\circ} \mathrm{C}$ for $2-3 \mathrm{~h}$, and then the culture temperature was shifted to $28^{\circ} \mathrm{C}$ to induce the protein expression for $6 \mathrm{~h}$. The induced cells centrifuged at $4{ }^{\circ} \mathrm{C}$ and $7500 \times g$ for $15 \mathrm{~min}$ and subjected to ultrasonic disruption with $150 \mathrm{~W}$ (JY96-IIN, Shanghai, China). The insoluble debris was removed by centrifuged at $4{ }^{\circ} \mathrm{C}$ and $7500 \times g$ for $15 \mathrm{~min}$, and the supernatant was harvested as crude protein $(21.99 \mathrm{mg})$. Purification of $\mathrm{rPsLeuDH}$ with the His-tagged was purified using Ni-NTA affinity chromatography. The purified protein $(1.11 \mathrm{mg})$ was eluted with 10, 50, 100 and $250 \mathrm{mM}$ imidazole buffer $(20 \mathrm{mM}$ Tris- $\mathrm{HCl}, 500 \mathrm{mM} \mathrm{NaCl}, \mathrm{pH} 8.0)$ at a flow rate of $1.0 \mathrm{~mL} / \mathrm{min}$. The purity and the molecular mass of the rPsLeuDH were determined by SDS-PAGE, using 12.0\% polyacrylamide gels.

\subsection{Assay of rPsLeuDH Activity}

The standard enzyme assay were based on traditional method and modified on basis $[1,30]$. The oxidation reaction activity assay was determined by $200 \mu \mathrm{L}$ reaction system. It contained $0.1 \mathrm{M}$ Glycine- $\mathrm{NaOH}$ ( $\mathrm{pH} 10.4)$ buffer, $10 \mathrm{mM}$ L-leucine and $10 \mu \mathrm{L}$ purified enzyme $(0.62 \mu \mathrm{g})$, which incubated at $30{ }^{\circ} \mathrm{C}$ for $2 \mathrm{~min}$. After adding $1 \mathrm{mM} \mathrm{NAD}^{+}$, the changes of absorbance at $340 \mathrm{~nm}$ within $1 \mathrm{~min}$ were detected. Futhermore, the reductive amination reaction system containing ( $200 \mu \mathrm{L}) 0.2 \mathrm{M}$ $\mathrm{NH}_{4} \mathrm{Cl}-\mathrm{NH}_{4} \mathrm{OH}$ buffer ( $\mathrm{pH}$ 9.0), $5 \mathrm{mM}$ TMP and $10 \mu \mathrm{L}$ purified enzyme at $30{ }^{\circ} \mathrm{C}$ for $2 \mathrm{~min}$, after 
adding $0.2 \mathrm{mM} \mathrm{NADH}$, changes in absorbance at $340 \mathrm{~nm}$ within $1 \mathrm{~min}$ were measured. One unit of LeuDH activity was defined as the amount of enzyme catalyzed the formation or reduction of $1 \mu \mathrm{moL}$ $\mathrm{NADH} / \mathrm{min}$ at $30^{\circ} \mathrm{C}$.

\subsection{Characterization of the Purified $r P s L e u D H$}

The optimal temperature of the purified $\mathrm{rPsLeuDH}$ was determined with the standard assay at temperatures from $0{ }^{\circ} \mathrm{C}$ to $60^{\circ} \mathrm{C}$. To evaluate the thermostability, the purified enzyme was incubated at three different temperatures $\left(30,40\right.$, and $\left.50{ }^{\circ} \mathrm{C}\right)$ for $120 \mathrm{~min}$, and the residual activity was measured by the standard enzyme assays. The optimal $\mathrm{pH}$ of the purified enzyme was determined at $30{ }^{\circ} \mathrm{C}$ using Citric acid $/ \mathrm{Na}_{2} \mathrm{HPO}_{4}$ buffer $(0.2 \mathrm{M})$ and $\mathrm{NH}_{4} \mathrm{Cl}-\mathrm{NH}_{4} \mathrm{OH}$ buffer $(0.2 \mathrm{M})$ for $\mathrm{pH}$ ranges $4.0-8.0$ and 8.0-10.0, respectively. To assess $\mathrm{pH}$ stability, the $\mathrm{rPsLeuDH}$ was pretreated at $\mathrm{pH} 4.0-11.0$ in the absence of substrate at $30^{\circ} \mathrm{C}$ for $30 \mathrm{~min}$, and the residual activity was measured by the standard enzyme assays. The purified rPsLeuDH was incubated at $0-3.0 \mathrm{M} \mathrm{NaCl}$ at $30^{\circ} \mathrm{C}$ for $30 \mathrm{~min}$, and remaining activity was assayed with the standard enzyme assays. The effects of different reagents on the rPsLeuDH activity were assayed with the standard enzyme assay after pre-incubating enzyme in different metal ions at $30^{\circ} \mathrm{C}$ for $30 \mathrm{~min}$. Enzyme activity assayed without any reagent was defined as control (100\%).

\subsection{Kinetic Parameter of the rPsLeuDH}

To assess the kinetics parameters, the Lineweaver-Burk plot method was used to calculate the $K_{\mathrm{m}}$ and $V_{\mathrm{m}}$ of rPsLeuDH [31]. The kinetic constants of NADH $(0.025 \mathrm{mM}-0.4 \mathrm{mM})$, L-leucine $(0.05 \mathrm{mM}-2 \mathrm{mM})$, L-tyrosine $(0.05 \mathrm{mM}-2 \mathrm{mM})$, L-proline $(0.05 \mathrm{mM}-2 \mathrm{mM})$, DL-methionine

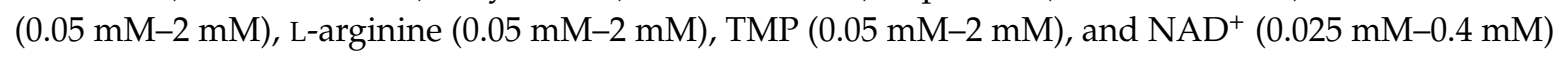
were determined by the above method in $\mathrm{rPLeuDH}$.

\subsection{Thermodynamic Parameter of the rPsLeuDH}

The $k_{\text {cat }}$ parameter is the reaction rate constant for the enzymatic-substrate complex chemical conversion into the enzyme and the product. $k_{\text {cat }}$ was calculated based on kinetics experiments, and the thermodynamic related parameters were assayed by the modification method of Feller [27] as follows:

$$
\begin{gathered}
k_{\mathrm{cat}}=A e^{\frac{-E_{\mathrm{a}}}{R T}} \\
\Delta H=E_{\mathrm{a}}-R T \\
\Delta S=R\left(\operatorname{In} k_{\mathrm{cat}}-24.76-\operatorname{InT}+\frac{E_{\mathrm{a}}}{R T}\right) \\
\Delta G=\Delta H-T \Delta S
\end{gathered}
$$

where $A$ is the constant, $E_{\mathrm{a}}$ is the activation energy of the reaction, $R$ is the gas constant $\left(8.314 \mathrm{~J} \mathrm{~mol}^{-1}\right.$ $\mathrm{K}^{-1}$ ), $\Delta H$ is the enthalpy of activation, $\Delta S$ is the entropy of activation, and $\Delta G$ is the free energy of activation.

\section{Conclusions}

A novel cold-adapted leucine dehydrogenase gene (psleudh) was cloned from Antarctic sea-ice bacterium and expressed in E. coli (DE3). Through homology modeling and comparison with its homologous enzyme (BsLeuDH), it was suggested that more glycine residues, reduced proline residues and arginine residues might be responsible for its catalytic efficiency at low temperature. rPsLeuDH was purified and characterized with higher activity at $30^{\circ} \mathrm{C}$, high salt $(3.0 \mathrm{M})$, remarkable $\mathrm{pH}$ stability ( $\mathrm{pH} 6.0-10.0)$, and higher specific activity $(275.13 \mathrm{U} / \mathrm{mg}$ ). These unique properties of rPsLeuDH make it a promising candidate as a biocatalyst in the enzymatic production of L-tert-leucine at room temperature. 
Author Contributions: Y.W., Y.H. and Q.W. took charge of the research and designed the experiments; Y.W., L.Z., X.X., K.P., R.L., Y.W. and Y.H. performed the experiments and analyzed the data; Y.W. and Q.W. wrote the paper.

Funding: This research was funded by the National Natural Science Foundation of China (41876149), the Natural Science Foundation of Shandong Province (ZR2017MC046) and the Key Research and Development Plan of Shandong Province (2018GHY115021).

Conflicts of Interest: The authors declare no conflict of interest.

\section{References}

1. Ohshima, T.; Wandrey, C.; Sugiura, M.; Soda, K. Screening of thermostable leucine and alanine dehydrogenases in thermophilic Bacillus strains. Biotechnol. Lett. 1985, 7, 871-876. [CrossRef]

2. Sanwal, B.D.; Zink, M.W. L-leucine dehydrogenase of Bacillus cereus. Arch. Biochem. Biophys. 1961, 94, 430-435. [CrossRef]

3. Nagata, S.; Bakthavatsalam, S.; Galkin, A.G.; Asada, H.; Sakai, S.; Esaki, N.; Soda, K.; Ohshima, T.; Nagasaki, S.; Misono, H. Gene cloning, purification, and characterization of thermostable and halophilic leucine dehydrogenase from a halophilic thermophile, Bacillus licheniformis TSN9. Appl. Microbiol. Biotechnol. 1995, 44, 432-438. [CrossRef] [PubMed]

4. Katoh, R.; Nagata, S.; Misono, H. Cloning and sequencing of the leucine dehydrogenase gene from Bacillus sphaericus, IFO 3525 and importance of the C-terminal region for the enzyme activity. J. Mol. Catal. B Enzym. 2003, 23, 239-247. [CrossRef]

5. Mahdizadehdehosta, R.; Kianmehr, A.; Khalili, A. Isolation and characterization of leucine dehydrogenase from a thermophilic Citrobacter freundii JK-91 strain isolated from Jask Port. Iran. J. Microbiol. 2013, 5, 278-284. [PubMed]

6. Zhu, W.J.; Li, Y.; Jia, H.H.; Wei, P.; Zhou, H.; Jiang, M. Expression, purification and characterization of a thermostable leucine dehydrogenase from the halophilic thermophile Laceyella sacchari. Biotechnol. Lett. 2016, 38, 855-861. [CrossRef] [PubMed]

7. Zhao, Y.; Wakamatsu, T.; Doi, K.; Sakuraba, H.; Ohshima, T. A psychrophilic leucine dehydrogenase from Sporosarcina psychrophila: Purification, characterization, gene sequencing and crystal structure analysis. J. Mol. Catal. B Enzym. 2012, 83, 65-72. [CrossRef]

8. Turnbull, A.P.; Ashford, S.R.; Baker, P.J.; Rice, D.W.; Rodgers, F.H.; Stillman, T.J.; Hanson, R.L. Crystallization and quaternary structure analysis of the $\mathrm{NAD}(+)$-dependent leucine dehydrogenase from Bacillus sphaericus. J. Mol. Biol. 1994, 236, 663-665. [CrossRef] [PubMed]

9. Zhu, L.; Wu, Z.; Jin, J.M.; Tang, S.Y. Directed evolution of leucine dehydrogenase for improved efficiency of L-tert-leucine synthesis. Appl. Microbiol. Biotechnol. 2016, 100, 5805-5813. [CrossRef] [PubMed]

10. Galkin, A.; Kulakova, L.; Ashida, H.; Sawa, Y.; Esaki, N. Cold-adapted alanine dehydrogenases from two Antarctic bacterial strains: Gene cloning, protein characterization, and comparison with mesophilic and thermophilic counterparts. Appl. Environ. Microb. 1999, 65, 4014-4020.

11. Gerday, C.; Aittaleb, M.; Bentahir, M.; Chessa, J.P.; Claverie, P.; Collins, T.; D'Amico, S.; Dumont, J.; Garsoux, G.; Georlette, D.; et al. Cold-adapted enzymes: From fundamentals to biotechnology. Trend Biotechnol. 2000, 18, 103-107. [CrossRef]

12. Jiang, W.; Sun, D.F.; Lu, J.X.; Wang, Y.L.; Wang, S.Z.; Zhang, Y.H.; Fang, B.S. A cold-adapted leucine dehydrogenase from marine bacterium Alcanivorax dieselolei: Characterization and L-tert-leucine production. Eng. Life Sci. 2016, 16, 283-289. [CrossRef]

13. Shi, Y.L.; Wang, Q.F.; Hou, Y.H.; Hong, Y.Y.; Han, X.; Yi, J.L.; Qu, J.J.; Lu, Y. Molecular cloning, expression and enzymatic characterization of glutathione s-transferase from Antarctic sea-ice bacteria Pseudoalteromonas sp. ANT506. Microbiol. Res. 2014, 169, 179-184. [CrossRef] [PubMed]

14. Wang, Y.T.; Han, H.; Cui, B.Q.; Hou, Y.H.; Wang, Y.F.; Wang, Q.F. A glutathione peroxidase from Antarctic psychrotrophic bacterium Pseudoalteromonas sp. ANT506: Cloning and heterologous expression of the gene and characterization of recombinant enzyme. Bioengineered 2017, 8, 742-749. [CrossRef] [PubMed]

15. Kuroda, S.I.; Tanizawa, K.; Sakamoto, Y.; Tanaka, H.; Soda, K. Alanine dehydrogenases from two Bacillus species with distinct thermostabilities: Molecular cloning, DNA and protein sequence determination, and structural comparison with other NAD(P)(+)-dependent dehydrogenases. Biochemistry 1990, 29, 1009-1015. [CrossRef] [PubMed] 
16. Baker, P.J.; Turnbull, A.P.; Sedelnikova, S.E.; Stillman, T.J.; Rice, D.W. A role for quaternary structure in the substrate specificity of leucine dehydrogenase. Structure 1995, 3, 693-705. [CrossRef]

17. Paredes, D.I.; Watters, K.; Pitman, D.J.; Bystroff, C.; Dordick, J.S. Comparative void-volume analysis of psychrophilic and mesophilic enzymes: Structural bioinformatics of psychrophilic enzymes reveals sources of core flexibility. BMC Struct. Biol. 2011, 11, 42-50. [CrossRef] [PubMed]

18. Li, F.L.; Shi, Y.; Zhang, J.X.; Gao, J.; Zhang, Y.W. Cloning, expression, characterization and homology modeling of a novel water-forming NADH oxidase from Streptococcus mutans ATCC 25175. Int. J. Biol. Macromol. 2018, 113, 1073-1079. [CrossRef] [PubMed]

19. Mohammadi, S.; Parvizpour, S.; Razmara, J.; Abu Bakar, F.D.; Illias, R.M.; Mahadi, N.M.; Murad, A.M. Structure prediction of a novel Exo- $\beta-1,3-$ Glucanase: Insights into the cold adaptation of psychrophilic yeast Glaciozyma antarctica PI12. Interdiscip. Sci. Comput. Life Sci. 2016, 10, 157-168. [CrossRef] [PubMed]

20. Herning, T.; Yutani, K.; Inaka, K.; Kuroki, R.; Matsushima, M.; Kikuchi, M. Role of proline residues in human lysozyme stability: A scanning calorimetric study combined with X-ray structure analysis of proline mutants. Biochemistry 1992, 31, 7077-7085. [CrossRef] [PubMed]

21. Siglioccolo, A.; Gerace, R.; Pascarella, S. "Cold spots” in protein cold adaptation: Insights from normalized atomic displacement parameters (B'-factors). Biophys. Chem. 2010, 153, 104-114. [CrossRef] [PubMed]

22. Li, J.; Pan, J.; Zhang, J.; Xu, J.H. Stereoselective synthesis of L-tert-leucine by a newly cloned leucine dehydrogenase from Exiguobacterium sibiricum. J. Mol. Catal. B Enzym. 2014, 105, 11-17. [CrossRef]

23. Feller, G.; Narinx, E.; Arpigny, J.L.; Aittaleb, M.; Baise, E.; Genicot, S.; Gerday, C. Enzymes from psychrophilic organisms. FEMS Microbiol. Rev. 1996, 18, 189-202. [CrossRef]

24. Ohshima, T.; Nishida, N.; Bakthavatsalam, S.; Kataoka, K.; Takada, H.; Yoshimura, T.; Soda, K.; Esaki, N. The purification, characterization, cloning and sequencing of the gene for a halostable and thermostable leucine dehydrogenase from Thermoactinomyces intermedius. Eur. J. Biochem. 1994, 222, 305-312. [CrossRef] [PubMed]

25. Michetti, D.; Brandsdal, B.O.; Bon, D.; Isaksen, G.V.; Tiberti, M.; Papaleo, E. A comparative study of cold- and warm-adapted endonucleases a using sequence analyses and molecular dynamics simulations. PLoS ONE 2017, 12, e0169586. [CrossRef] [PubMed]

26. Pawlak-Szukalska, A.; Wanarska, M.; Popinigis, A.T.; Kur, J. A novel cold-active $\beta$-D-galactosidase with transglycosylation activity from the Antarctic Arthrobacter sp. 32cB-Gene cloning, purification and characterization. Process Biochem. 2014, 49, 2122-2133. [CrossRef]

27. Lonhienne, T.; Gerday, C.; Feller, G. Psychrophilic enzymes: Revisiting the thermodynamic parameters of activation may explain local flexibility. Biochim. Biophys. Acta 2000, 1543, 1-10. [CrossRef]

28. Khrapunov, S.; Chang, E.; Callender, R.H. Thermodynamic and structural adaptation differences between the mesophilic and psychrophilic lactate dehydrogenases. Biochemistry 2017, 56, 3587-3595. [CrossRef] [PubMed]

29. Robert, X.; Gouet, P. Deciphering key features in protein structures with the new ENDscript server. Nucleic Acids Res. 2014, 42, W320-W324. [CrossRef] [PubMed]

30. Ohshima, T.; Nagata, S.; Soda, K. Purification and characterization of thermostable leucine dehydrogenase from Bacillus stearothermophilus. Arch. Microbiol. 1985, 141, 407-411. [CrossRef]

31. Shang, Z.C.; Zhang, L.L.; Wu, Z.J.; Gong, P.; Li, D.P.; Zhu, P.; Gao, H.J. The activity and kinetic parameters of oxidoreductases in phaeozem in response to long-term fertiliser management. J. Soil Sci. Plant Nutr. 2012, 12, 597-607. [CrossRef]

(C) 2018 by the authors. Licensee MDPI, Basel, Switzerland. This article is an open access article distributed under the terms and conditions of the Creative Commons Attribution (CC BY) license (http://creativecommons.org/licenses/by/4.0/). 